\title{
Implementasi Sistem Informasi Akuntansi Pembayaran Sumbangan Pembinaan Pendidikan Pada Lembaga Pendidikan Tingkat Menengah
}

\author{
Rizka Apriliana ${ }^{1}$, Rifa Nurafifah Syabaniah ${ }^{2 *}$, Andi Riyanto ${ }^{3}$ \\ 1,3 Sistem Informasi Akuntansi, Fakultas Teknik dan Informatika, Universitas Bina Sarana \\ Informatika, Kota Sukabumi, Indonesia. \\ ${ }^{2 *}$ Sistem Informasi, Fakultas Teknik dan Informatika, Universitas Bina Sarana Informatika, Kota \\ Sukabumi, Indonesia. \\ Email: ${ }^{1}$ rizka@bsi.ac.id, 2rifa.rrf@bsi.ac.id, ${ }^{3}$ andi.iio@bsi.ac.id
}

\begin{abstract}
SMA Plus Yaspida Sukabumi is an institution engaged in the field of education by combining modern boarding schools and schools. Until now, the process of SPP payment transactions by recording reports into the ledger. The problem that is always faced is the difficulty of finding data which takes quite a long time from the process of searching for data with a large amount of data in the payment data archive. The method of collecting data in this research is by means of observations, interviews and literature studies as well as the development of information systems in making applications using the waterfall method, and the programming language used is PHP, and the MYSQL database. The results of the design of an accounting information system designed to make it easier to search for data in the transaction process and report generation can be done easily and automatically So that the payment transaction process can be carried out effectively and efficiently and can minimize the risk of errors caused by human error.
\end{abstract}

Keywords: Accounting information system, SPP payment system

\begin{abstract}
Abstrak
SMA Plus Yaspida Sukabumi merupakan lembaga yang bergerak dalam bidang pendidikan dengan memadukan pesantren modern dan sekolah. sampai saat ini proses transaksi pembayaran SPP dengan pencatatan laporan mencatat kedalam buku besar. masalah yang selalu dihadapi adalah sulitnya pencarian data yang membutuhkan waktu cukup lama dari proses mencari data dengan jumlah data yang banyak pada arsip data pembayaran. metode pengumpulan data pada penelitian ini dengan cara pengamatan, wawancara dan studi pustaka serta pengembangan sistem informasi dalam pembuatan aplikasi menggunakan metode waterfall, dan bahasa pemrograman yang dipakai adalah PHP, serta database MYSQL. Hasil rancangan sistem informasi akuntansi yang dirancang bertujuan untuk memudahkan dalam pencarian data dalam proses transaksi dan pembuatan laporan dapat dilakukan dengan mudah dan otomatis. Sehingga proses transaksi pembayaran dapat dilakukan dengan efektif dan efisien serta dapat meminimalisir resiko kesalahan yang diakibatkan oleh human error.
\end{abstract}

Kata Kunci: Sistem informasi akuntansi, Sistem pembayaran SPP

\section{PENDAHULUAN}

SPP adalah Sumbangan Pembinaan Pendidikan, pembiayaan pendidikan adalah sisi anggaran penerimaan dan anggaran pengeluaran. Anggaran penerimaan adalah pendapatan perolehan setiap tahun oleh sekolah, baik rutin maupun insidental, yang diterima dari berbagai sumber resmi. Sedangkan anggaran pengeluaran adalah jumlah uang yang dibelanjakan setiap tahun 
untuk kepentingan pelaksanaan pendidikan sekolah. (Wisni, 2020). Sedangkan Sistem pembayaran adalah suatu sistem yang mencakup pengaturan, kontrak/perjanjian, fasilitas operasional, dan mekanisme teknis yang digunakan untuk penyampaian, pengesahan dan penerimaan instruksi pembayaran, serta pemenuhan kewajiban pembayaran melalui pertukaran nilai" antar perorangan, bank, dan lembaga lainnya baik domestik maupun antar negara. (Mulyani, 2016) Dalam prakteknya,transaksi pembayaran dilakukan dengan instrumen tunai dan non tunai.

SMA Plus Yaspida Sukabumi merupakan salah satu yayasan pendidikan formal untuk mendidik anak-anak setingkat sekolah menengah atas, saat ini proses pembayaran Sumbangan Pembinaan Pendidikan (SPP) di SMA Plus Yaspida Sukabumi masih manual. Permasalahan yang sering terjadi adalah dalam pelaksanaan proses pembayaran SPP sering lambat dikarenakan tidak adanya sistem yang mampu membantu proses pembayaran, selain itu juga akan memperlambat kinerja staff tata usaha dan kurang akuratnya perhitungan sehingga sering terjadi kesalahan pada hasil akhir, untuk pelaporan bisa dipastikan terhambat dikarenakan lambatnya proses - proses pembayaran. Agar proses pencatatan dan pelaporan pembayaran SPP dapat dilakukan lebih efektif. Maka sekolah membutuhkan sistem yang dapat membantu permasalahan yang ada. Berfungsi untuk mempermudah bendahara dan staf tata usaha saat pembuatan laporan pembayaran SPP hal tersebut dapat diajukan sebagai bahan penelitian

\subsection{Teknik Pengumpulan Data}

\section{METODE PENELITIAN}

Metode penelitian pada penelitian ini dilakukan dengan cara memperoleh data, fakta serta informasi-informasi yang berkembang dengan masalah menggunakan teknik-teknik pengumpulan data sebagai berikut:

1. Observasi, yaitu pengamatan yang khusus dan secara langsung dan untuk mendapatkan data-data yang diperlukan serta untuk mengetahui permasalahan yang dihadapi.

2. Study Pustaka, Metode ini untuk mendukung data yang telah didapat dari data primer dengan referensi jurnal (prosedur,buku atau karya ilmiah) pada bidang yang berkaitan dengan penyusunan tugas akhir. Metode yang digunakan untuk mendukung data primer yang diambil.

3. Wawancara, Memperoleh data dengan bertanya langsung kepada karyawan yang berwenang dan menguasai bidang ini. Pada metode ini sebelumnya penulis menyusun pertanyaan - pertanyaan yang akan diajukan kepada karyawan terlebih dahulu untuk mengumpulkan data mengenai pembayaran Sumbangan Pembinaan Pendidikan (SPP) yang sedang dijalan kan di SMA Plus Yaspida Sukabumi.

\subsection{Metode Pengembangan Software}

Metode pengembangan software yang digunakan yaitu metode waterfall (air terjun). metode waterfall adalah mode klasik (classic life cycle), dimana metode ini menggambarkan pendekatan yang sistematis dan juga berurutan pada pengembangan perangkat lunak. (Pressman, 2015)

1. Analisis kebutuhan software

Analisa kebutuhan perangkat lunak merupakan suatu bentuk kegiatan dalam upaya mencari informasi dan apa saja yang diperlukan dalam pembuatan perangkat lunak.

2. Desain

Perancangan (design) merupakan penggambaran, perencanaan dan pembuatan sketsa atau pengaturan dari beberapa elemen yang terpisah didalam sistem dalam satu kesatuan yang utuh dan berfungsi dengan baik.

3. Code Generation

Menentukan bahasa pemrograman yang akan digunakan dalam membuat tugas akhir ini adalah menggunakan PHP.

4. Testing

Penguji merupakan suatu teknik investigasi yang dilakukan kepada sistem yang telah dibuat untuk mendapatkan informasi mengenai kualitas dari sistem yang sedang diuji.

5. Support

Pendukung merupakan proses yang dilakukan dalam pengubahan atau pengembangan dari perangkat lunak yang telah dibuat. 


\section{HASIL DAN PEMBAHASAN}

Sistem pembayaran SPP yang terdapat pada SMA Plus Yaspida sering menimbulkan masalah antara lain: Pencarian data sulit dan membutuhkan waktu yang lama, karena harus mencari data dengan jumlah yang banyak pada arsip data pembayaran. Selain itu kesulitan dalam pencocokan arsip pembayaran dan kartu pembayaran mengakibatkan lambatnya pada proses pembayaran dan memperlambat kinerja staff tata usaha. berakibat terjadinya kesalahan dalam pembuatan laporan pembayaran SPP.

Setelah menganalisa masalah, ditemukan alternatif pemecahan masalah dengan dibuat rancangan sistem informasi akuntansi pembayaran SPP dengan fasilitas tombol pencarian sehingga pencarian data dapat dilakukan dengan mudah dan cepat.

\subsection{Prosedur Sistem Berjalan Sistem Pembayaran SPP}

Berikut ini adalah sistem berjalan pembayaran SPP pada SMA Plus Yaspida:

1. Prosedur pembayaran SPP

Proses diawali dengan siswa datang ke kantor ke bagian tata usaha melakukan pembayaran SPP bulanan, kemudian siswa memberikan kartu dan uang untuk pembayaran ke bagian tata usaha lalu bagian tata usaha menerima kartu SPP dan uang dari siswa. Bagian tata usaha memeriksa uang apakah jumlah uang yang diberikan sesuai, apabila tidak sesuai maka bagian tata usaha menginformasikan ke siswa. Kemudian bagian tata usaha akan mencatat pembayaran di kartu SPP dan di buku arsip pembayaran SPP lalu bagian tata usaha memberikan cap pada kartu SPP yang telah dibayar kemudian bagian tata usaha menyerahkan kembali kartu pembayaran SPP dan siswa menerima bukti pembayaran yaitu kartu SPP yang sudah di cap.

2. Prosedur Pembuatan Laporan SPP

Setiap akhir bulan, bagian tata usaha membuat laporan pembayaran SPP, kemudian bagian tata usaha memberikan hasil laporan pembayaran SPP kepada kepala sekolah.

\subsection{Use Case Diagram}

Rancangan Use case diagram system pembayaran SPP dirancang sebagai berikut:

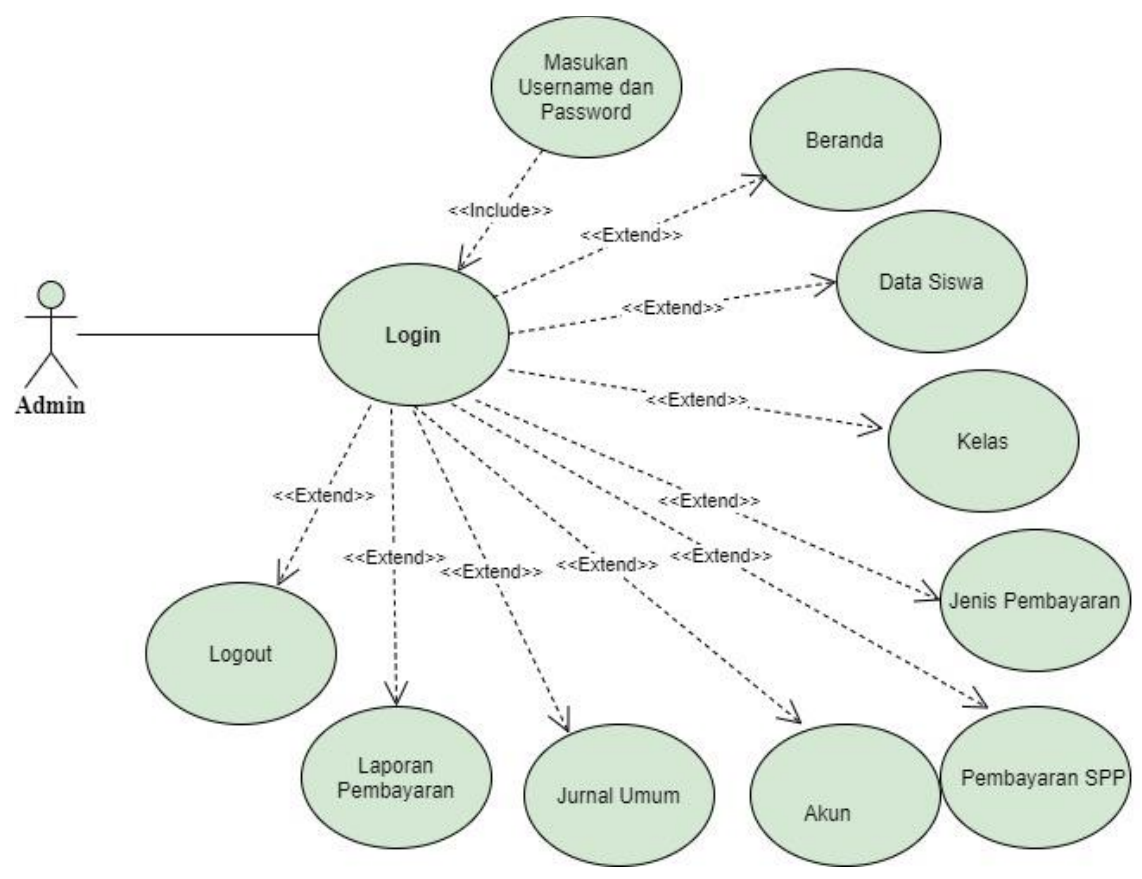

Gambar 1. Use Case diagram ramcangan system pembayaran SPP 


\subsection{Activity Diagram}

Adapun rancangan sistem pembayaran SPP berdasarkan aktipitas sistem dirancang dalam bentuk activity diagram sebagai berikut:

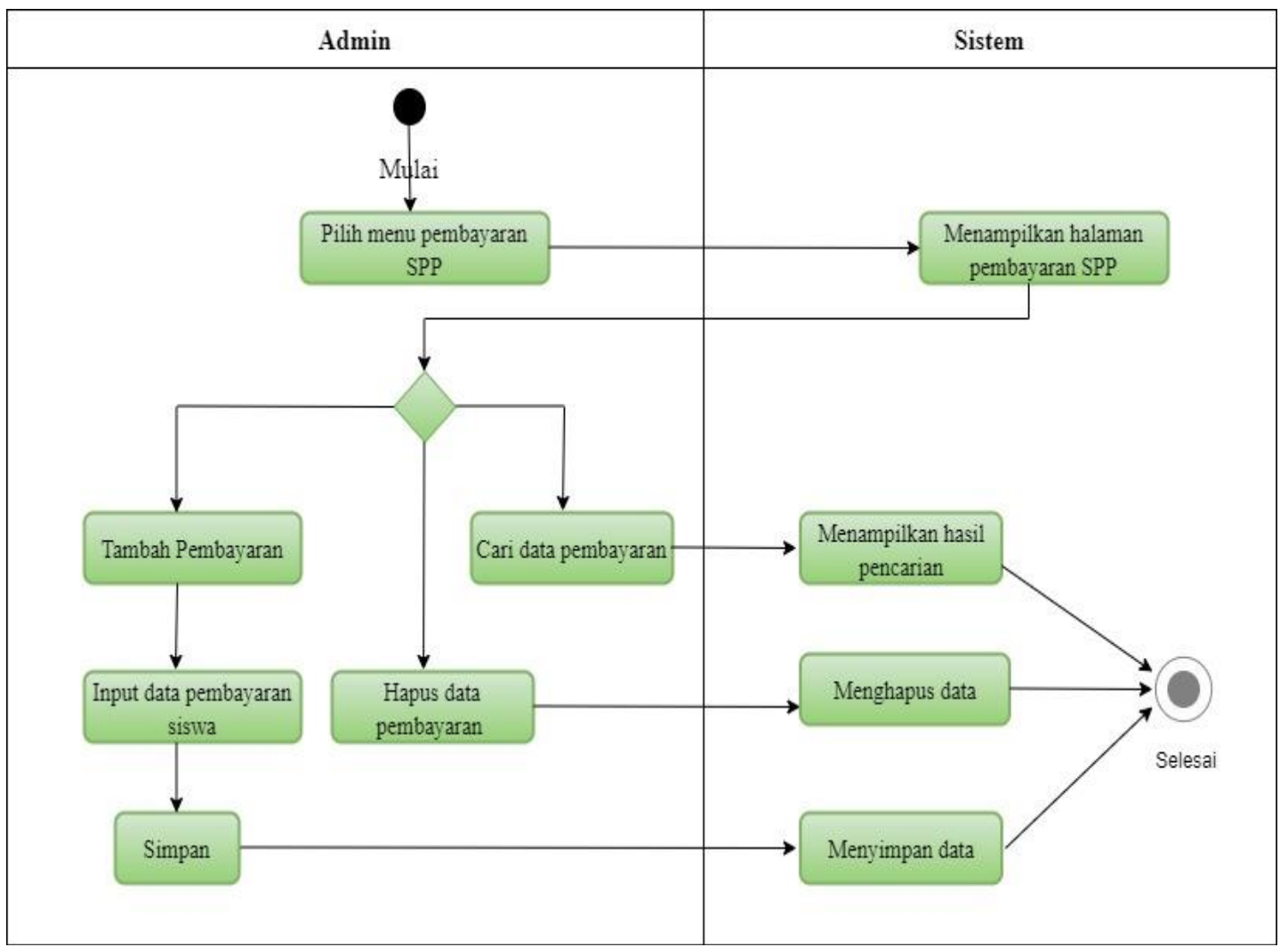

Gambar 2. Activity Diagram rancangan sistem pembayaran SPP

\subsection{Entity Relationship Diagram (ERD)}

Dibuat rancangan ERD untuk mempermudah penyimpanan data pada system pembayaran sebagai berikut:

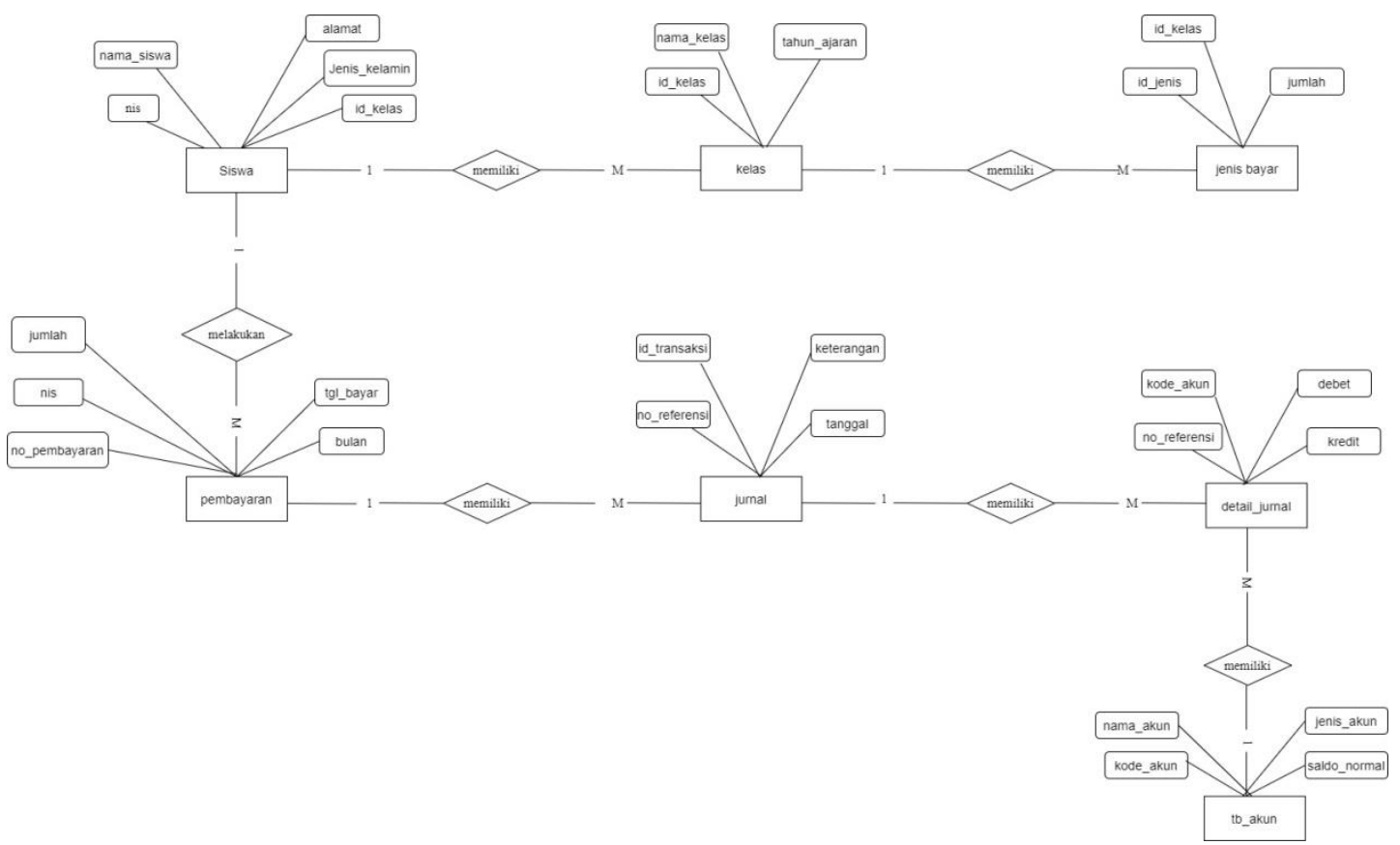




\subsection{User Interface}

Tampilan rancangan system Pembayaran SPP sesuai dengan rancangan Usecase diagram dan Activity diagram yang telah dirancang.

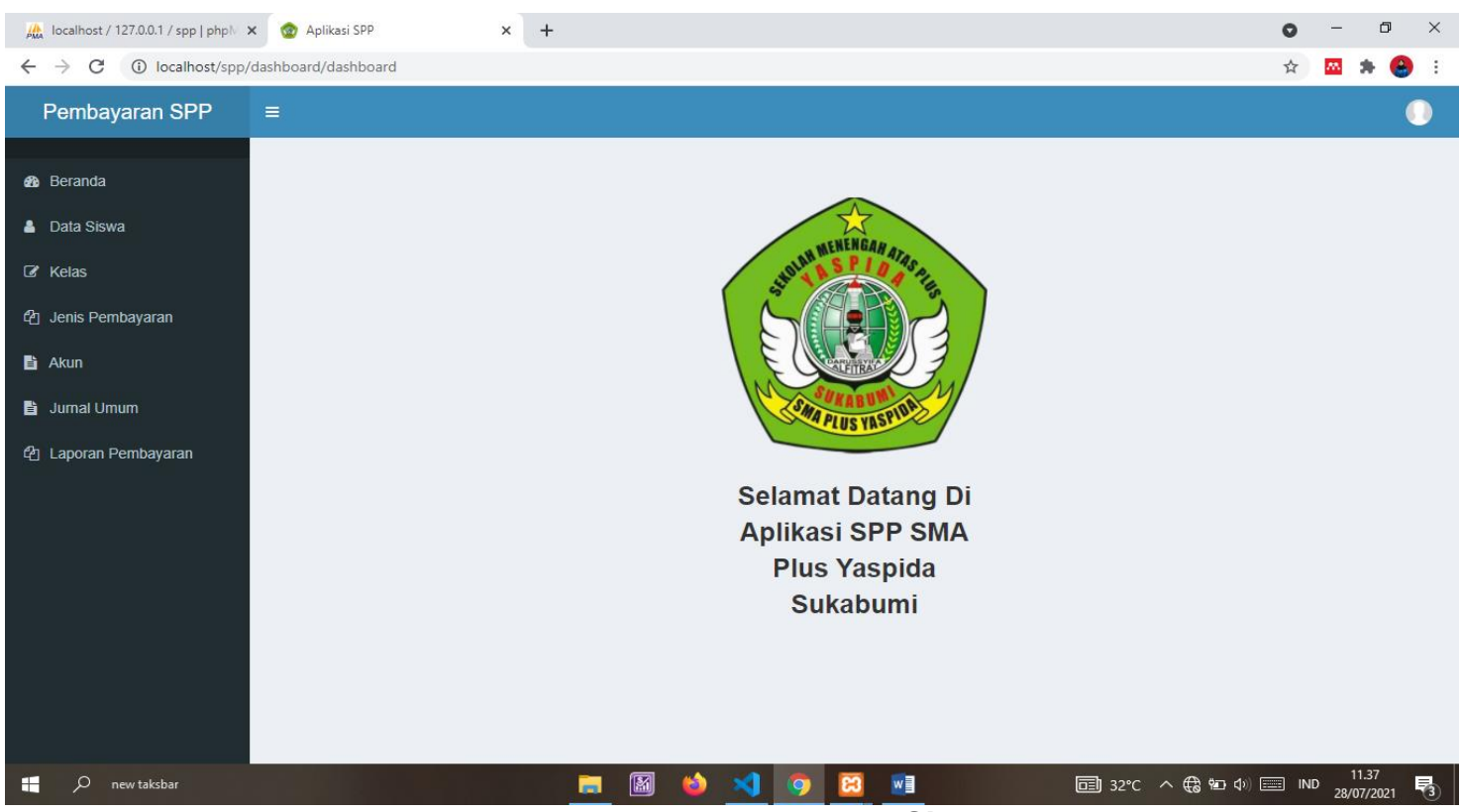

Gambar 4. Halaman Utama Sistem

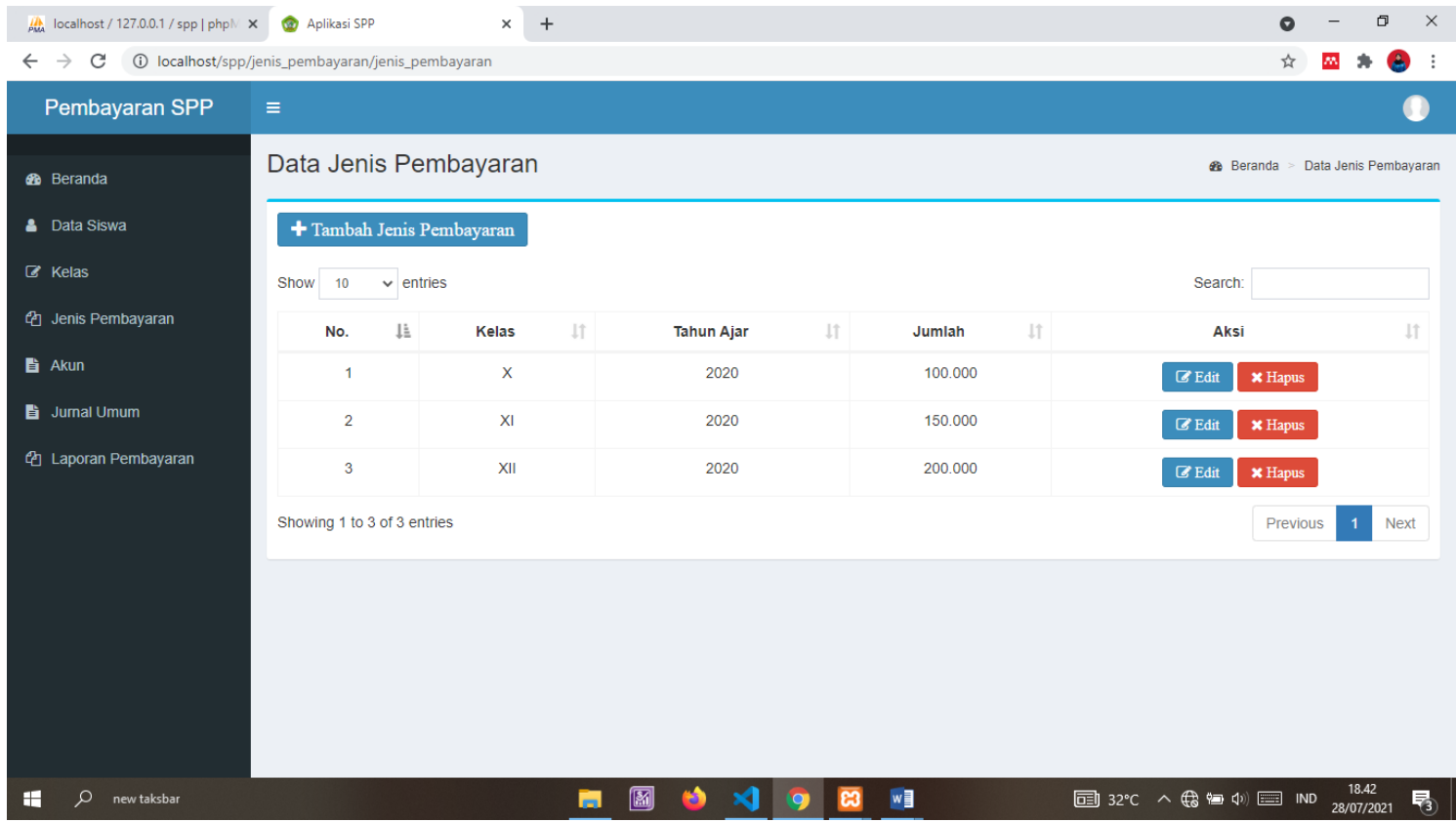

Gambar 5. Halaman Jenis Pembayaran 


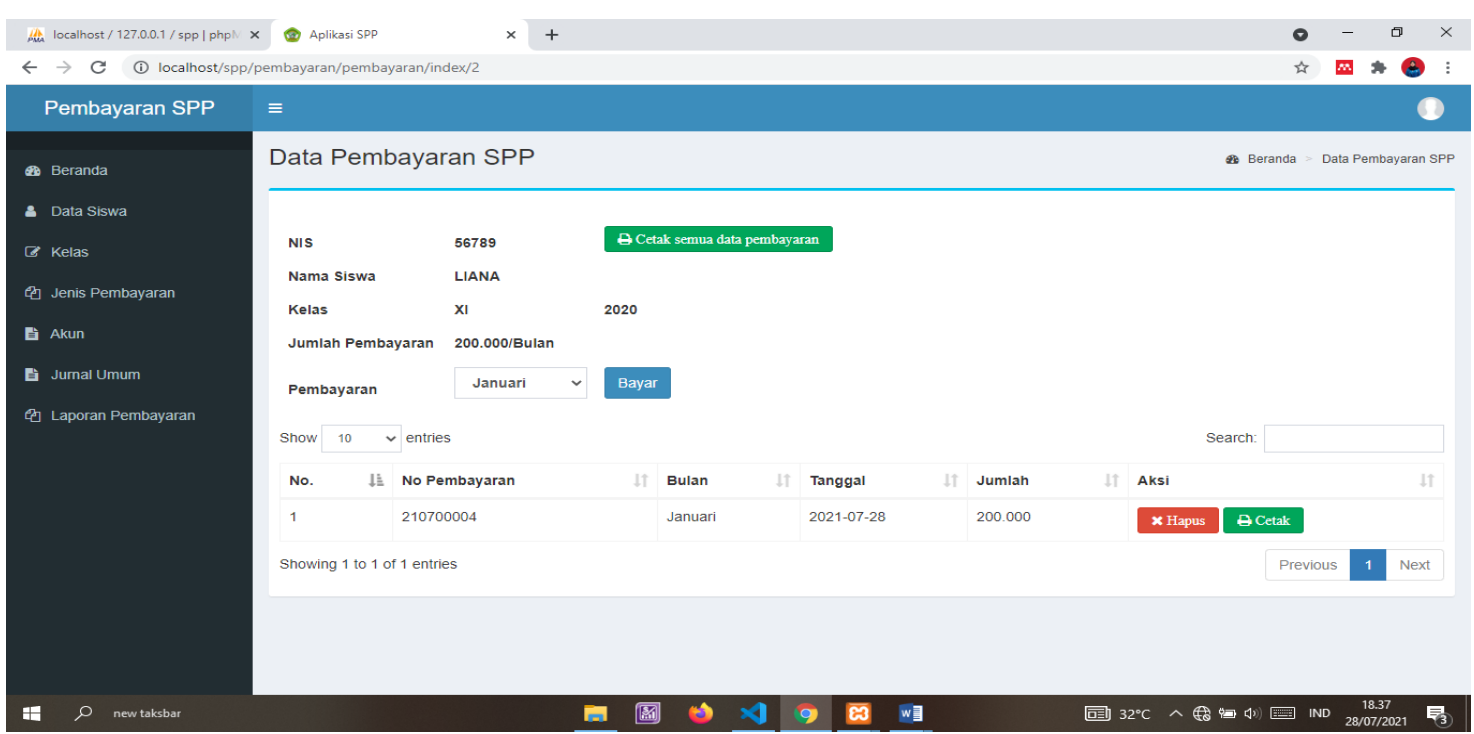

Gambar 6. Halaman Proses Pembayaran SPP

\section{KESIMPULAN}

Sistem administrasi pembayaran SPP pada SMA Plus Yaspida dilakukan secara manual dari segi proses transaksi pembayaran SPP dan pencatatan laporan penerimaan pembayaran SPP dengan menggunakan buku besar, sehingga menimbulkan masalah yang membutuhkan waktu cukup lama karena harus membuka arsip berupa kartu pembayaran, kwitansi, dan buku pencatatan yang memungkinkan beresiko arsip dapat rusak atau hilang.

Rancangan sistem informasi akuntansi pembayaran SPP secara terkomputerisasi yang memudahkan dalam proses administrasi pembayaran SPP serta meminilkan terjadinya kesalahan dalam proses transaksi dan pencatatan laporan penerimaan pembayaran SPP dengan Fasilitas tombol pencarian untuk pencarian data dapat di lakukan dengan mudah dan cepat serta proses pembayaran akan lebih cepat dan kinerja staff akan menjadi lebih efisien.

\section{UCAPAN TERIMAKASIH}

Terimakasih Kepada Pengurus SMA PLUS YASPIDA yang telah memberikan ijin kepada peneliti melasanakan pengamatan dan bersedia meluangkan waktu untuk wawancara.

\section{REFERENCES}

[1] N. Yuliana, "PENGGUNAAN MODEL PEMBELAJARAN DISCOVERY LEARNING DALAM PENINGKATAN HASIL BELAJAR SISWA DI SEKOLAH DASAR," Jurnal IImiah Pendidikan dan Pembelajaran, pp. 21-28, 2018.

[2] R. Ulfa, "VARIABEL PENELITIAN DALAM PENELITIAN PENDIDIKAN," Al-Fathonah : Jurnal Pendidikan dan Keislaman, pp. 342-245, 2021.

[3] I. m. Surdita, "Pengelempokan dan Klasifikasi Komputer: Dasar Sistem Komputer," 2015/2016.

[4] A. Y. Saputra1, "Sistem Pendukung Keputusan Dalam Memilih Lokasi Perumahan Dengan Metode Simple Multi Attribute Rating Technique," Cogito Smart Journal, vol. 5, no. 1, pp. 35-43, 2019.

[5] I. B. Y. B. I. M. P. D. M. R. S. I. M. A. W. sabella Soerjanto Putri, "GAMBARAN TINGKAT RISIKO PENYAKIT KARDIOVASKULAR PADA PASIEN DIABETES MELITUS TIPE 2 DI PUSKESMASKOTA DENPASAR," JURNAL MEDIKA UDAYANA, vol. 9, no. 11, pp. 62-67, 2020.

[6] I. M. O. A. Parwita, "Obat Tradisional," in Diktat, Bukit Jimbaran, Universitas Udayana, 2016, pp. 1-71.

[7] Nurhasanah, "PENDUKUNG KEPUTUSAN PENENTUAN PENERIMA BEASISWA MENGGUNAKAN METODE SMART( SIMPLE MULTI ATTRIBUTE RATING TECHNIQUE )," Majalah IImiah INTI, vol. XII, no. 1, pp. 60-66, 2017.

[8] F. K. A. Nichen Irma Cintia, "PENERAPAN MODEL PEMBELAJARAN DISCOVERY LEARNING UNTUK MENINGKATKAN KEMAMPUAN BERPIKIR KREATIF DAN HASIL BELAJAR SISWA," PERSPEKTIF IImu Pendidikan, pp. 69-77, 2018.

[9] A. L. W. E. Y. A. B. S. Jumayanti, "KUALITAS HIDUP PASIEN DENGAN PENYAKIT KARDIOVASKULAR DI YOGYAKARTA," Jurnal Kesehatan, vol. 13, no. 1, pp. 1-12, 2020.

[10] N. N. Y. M. Y. E. Jefrin Sambara, "Pemanfaatan Tanaman Obat Tradisional Oleh Masyarakat Kelurahan Merdeka Kecamatan Kupang Timur 2016," Jurnal Info Kesehatan, vol. 14, no. 1, pp. 1113- 
$1124,2016$.

[11] M. irawan Afrianto, "https://repository.unikom.ac.id," 18 september 2021. [Online]. Available: https://repository.unikom.ac.id.

[12] H. Indrayani, "Penerapan Teknologi Informasi dalam Peningkatan Efektivitas, Efisiensi dan Produktivitas Perusahaan," https://media.neliti.com.

[13] A. K. Indarto, "EXporasi Metode Pengobatan Tradisional Oleh Para Pengobat Tradisional di Wilayah Karesidenan Surakarta," Jurnal Terpadu IImu Kesehatan, vol. 7, no. 1, pp. 1-100, 2018.

[14] A. P. A. U. R. D. Hendy Lesmana, "Pengobatan Tradisional Pada Masyarakat Tidung Kota Tarakan:Study Kualitatif Kearifan Lokal Bidang Kesehatan," MEDISAINS-Jurnal ilmiah ilmu-ilmu Kesehatan, vol. 16, no. 1, pp. 31-41, 2018.

[15] A. Emda, "KEDUDUKAN MOTIVASI BELAJAR SISWA DALAM PEMBELAJARAN," Lantanida Journal, pp. 170-182, 2017.

[16] S. E. N. P. P. D. L. D. S. N. M. S. V. K. P. P. ,. W. A. Dian Yaniarti Hasanah, "Gangguan Kardiovaskular pada Infeksi COVID 19," Indonesian Journal of Cardiology, vol. 41, no. 2, pp. 59-68, 2020.

[17] S. R. Andani, "Penerapan Metode SMART Dalam Pengambilan Keputusan Penerima Beasiswa Yayasan AMIK Tunas Bangsa," Jurnal sistem dan teknologi informasi, vol. 7, no. 3, pp. 166-170, 2019. 